\title{
Dynamic locking screws in proximal humeral plate osteosynthesis demonstrate superior fixation properties: a biomechanical study
}

Gunther Sandmann ${ }^{1}$, Atesch Ateschrang ${ }^{2}$, Thomas Freude ${ }^{3}$, Ulrich Stöckle ${ }^{4}$, Werner Schmölz ${ }^{5}$, Christian Konrads ${ }^{2^{*}}$ (D) and Stefan Döbele ${ }^{2}$

\begin{abstract}
Purpose: Angular stable implants reduced the complication rate in the treatment of humeral head fractures. But the failure rate is still high. To further reduce the risk of cut-out, cement augmentation of screws was introduced. A reason for failure of plate osteosynthesis might be the extremely high stiffness of the screw-plate interface leading to a loss of reduction and cut-out of screws. A more homogeneous distribution of the forces on all screws may avoid secondary dislocation. We hypothesize that dynamic osteosynthesis minimizes screw loosening and results in a higher load to failure than standard locking screws.

Methods: Twelve paired human humerus specimens were analysed. A standardized three-part fracture model with a metaphyseal defect was simulated. Within each pair of humeri, one was fixed with a Philos plate and standard locking screws (LS), whereas the other humerus was fixed with a Philos plate and dynamic locking screws (DLS). A cyclic varus-bending test or a rotation test with increasing loading force was performed until failure of the screwbone-fixation.
\end{abstract}

Results: In the varus bending test, pairs failed by screw loosening in the humeral head. The LS-group reached 2901 (601-5201) load cycles until failure, while the DLS-group failed after 3731 (2001-5601) cycles. This corresponds to a median loading of $195 \mathrm{~N}$ for the LS-group and $235 \mathrm{~N}$ for the DLS-group $(p=0.028)$. In the rotation test the LS-group reached a median of 1101 (501-1501) load cycles until failure of fixation occurred, while the DLS-group failed after 1401 (401-2201) cycles $(p=0.225)$.

Conclusions: Plate fixation using dynamic locking screws for the treatment of proximal humerus fractures demonstrated more load cycles until failure compared to standard locking plate osteosynthesis.

Keywords: Proximal humeral fracture, Humeral head fracture, PHILOS, Reosteosynthesis

\footnotetext{
*Correspondence: christian.konrads@gmail.com

${ }^{2}$ Department of Trauma and Reconstructive Surgery, BG Klinik, University of

Tübingen, Schnarrenbergstr. 95, 72076 Tübingen, Germany

Full list of author information is available at the end of the article
}

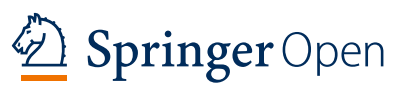

(c) The Author(s). 2020 Open Access This article is licensed under a Creative Commons Attribution 4.0 International License, which permits use, sharing, adaptation, distribution and reproduction in any medium or format, as long as you give appropriate credit to the original author(s) and the source, provide a link to the Creative Commons licence, and indicate if changes were made. The images or other third party material in this article are included in the article's Creative Commons licence, unless indicated otherwise in a credit line to the material. If material is not included in the article's Creative Commons licence and your intended use is not permitted by statutory regulation or exceeds the permitted use, you will need to obtain permission directly from the copyright holder. To view a copy of this licence, visit http://creativecommons.org/licenses/by/4.0/. 


\section{Background}

Proximal humeral fractures can be treated using several surgical and non-surgical concepts [5, 7, 25]. For stable fractures a non-operative treatment is recommended [7, 8]. Three- and four-part fractures could be handled with operative stabilization techniques including minimally invasive osteosynthesis, open reduction and plate fixation, intramedullary nail osteosynthesis, or primary arthroplasty [4, 11, 14, 15]. To prevent failures, it is essential to choose the most suitable treatment $[1,22,30]$.

The development and introduction of locking plates (Fig. 1) led to promising results [20]. However, the complication rate using locking plate osteosynthesis is still rather high in proximal humeral fractures. A multicenter study published in 2012 by Südkamp et al. encountered complications in $34 \%$ of 155 patients within 12 months postoperatively. The most common complication (14\%) was screw perforation of the humeral head [27]. Other authors also reported a high screw perforation rate

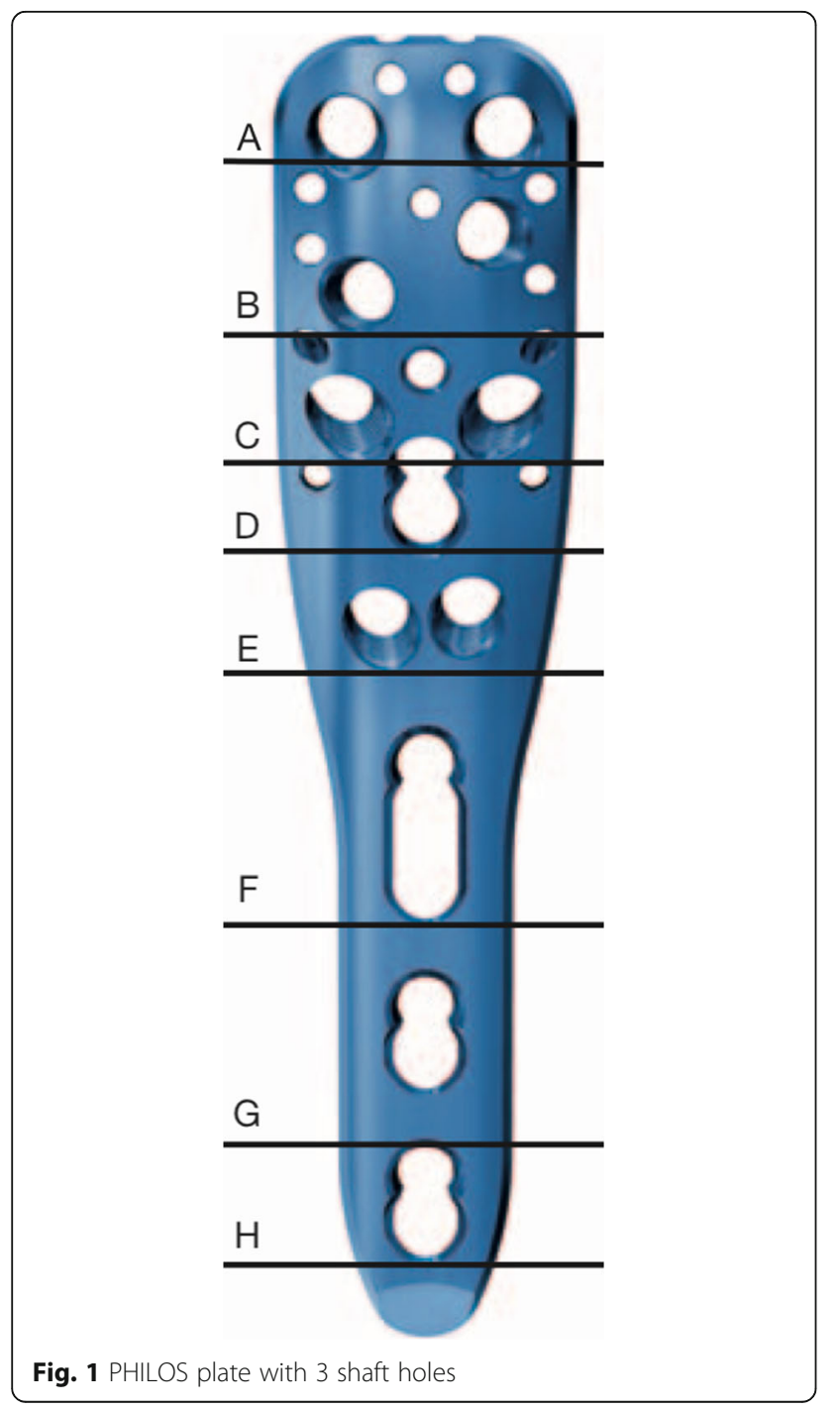

demonstrating that cut-out of screws was the most common complication within three postoperative months. A systematic review described an overall complication rate of $48.8 \%$, including a revision rate of $13.8 \%$. Varus malunion was observed in $16.3 \%$ of cases, osteonecrosis in $10.8 \%$, intraarticular screw perforation in $7.5 \%$ [26].

Therefore, adaptions to the implants have been made and by the use of medial calcar support by a blade device, secondary varus displacement could be reduced [24]. In severely displaced fractures and reduced bone quality the use of allograft struts leads to improved results [6]. In a comparative clinical trial, augmentation with calcium phosphate cement significantly decreased $(p=0.02)$ displacement and intraarticular screw perforation in fractures with metaphyseal comminution [21, 24]. In a biomechanical study, Unger et al. observed the effect of in situ augmentation on implant anchorage in proximal humeral fractures [28]. Augmentation of cannulated screws might be a practicable method to enhance screw anchorage [23]. Indeed, the use of cement augmentation improves screw anchorage and thereby reduces loss of reduction [3, 17]. But there are still cases, where the cement augmentation is not favorable and here the dynamic osteosynthesis might be a better choice [13].

Dynamic Locking Screws (DLS) are a further development of locking screws (Fig. 2). These screws allow for some movement of the outer part of the screw (threaded sleeve) relative to the core part (pin) of the dynamic head locking screw. These implants are used with standard locking plates. They are especially recommended in comminuted fractures treated with bridging plate osteosynthesis. Stiffness of the osteosynthesis is reduced, especially at the plate-sided parts of the fracture site, which usually is the tension side of the bone $[9,10]$. Several studies demonstrated that DLS could act like a damper [12]. We suppose that this might be especially beneficial in weak bone like the humeral head. Generally, DLS lead to a reduction of force peaks and thereby better stress distribution over all screws. Using DLS, an increased screw anchorage in the bone might be achievable even without augmentation.

The aim of the present biomechanical study was to evaluate implant anchorage with DLS versus standard locking screws (LS) in plate osteosynthesis of three-part proximal humeral fractures under cyclic loading in varus bending and rotation tests.

\section{Materials and methods}

A model of proximal humeral fracture plate osteosynthesis was used for ex-vivo biomechanical testing until failure by fragment dislocation. The applied test setup, loading protocol, and fracture model was adapted from a previously published study [28] investigating proximal 


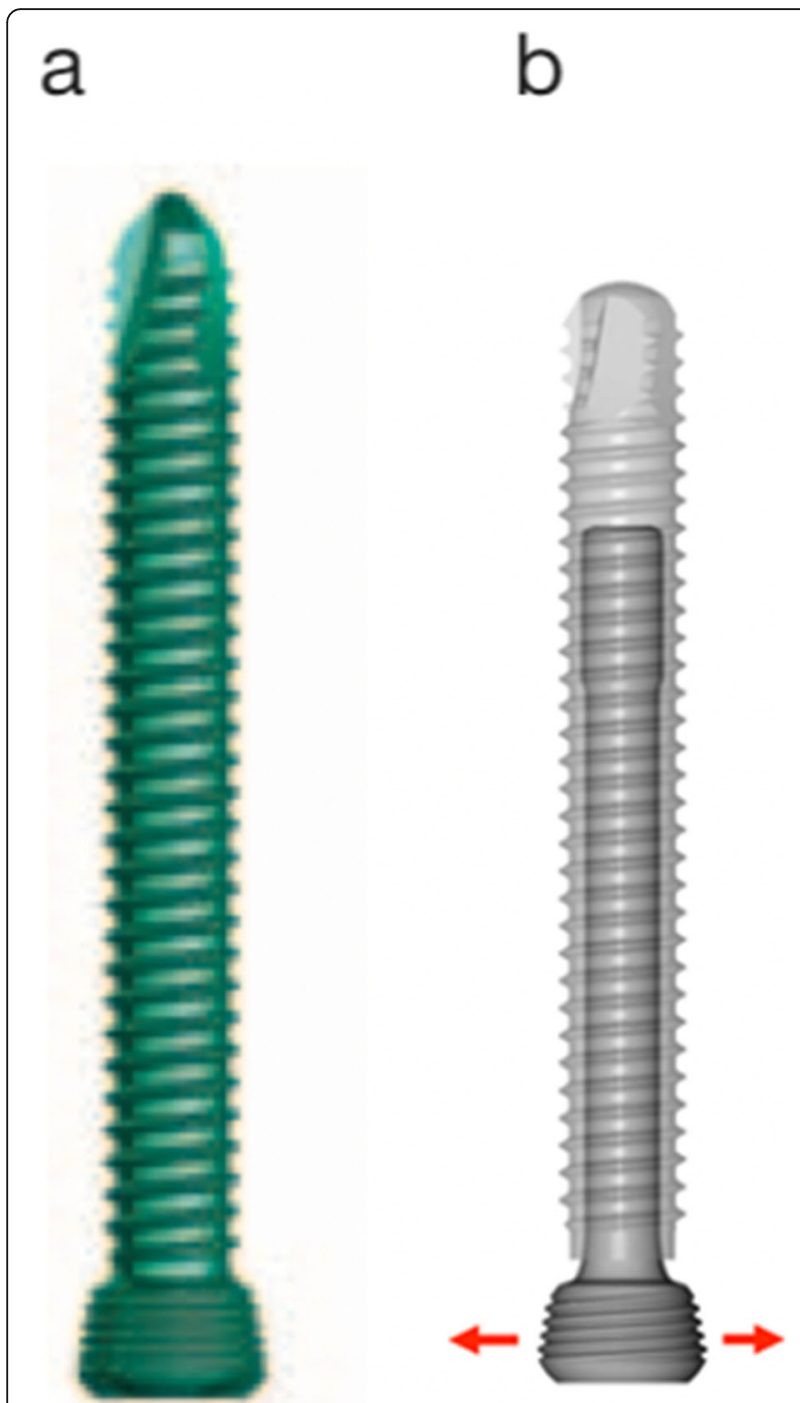

Fig. 2 Screw types. a Standard locking screw, b Dynamic locking screw

humeral fracture plate osteosynthesis and is described in the following.

\section{Specimens}

Twelve pairs $(n=24)$ of fresh frozen human cadaveric humeri (mean age $72.9+/-10.84$ years, 8 females and 3 males) were used for the tests. The Bone-MineralDensity (BMD) in the humeral head was assessed using the method described by Krappinger et al. [16]. Specimens were randomly distributed into four homogeneous groups regarding age, gender, and BMD. Within each pair of humeri one sample was randomised for DLS implantation.

A standardized three-part fracture of the humeral head with metaphyseal comminution was simulated. Fracture reduction and fixation was carried out with a PHILOS plate osteosynthesis (DePuy Synthes, Oberdorf,
Switzerland, Fig. 1). For fixation of the PHILOS plate (Section A-C) 6 head locking screws (LS $3.5 \mathrm{~mm}$, Fig. 2a) or 6 dynamic head locking screws (DLS $3.7 \mathrm{~mm}$, Fig. 2b) were used. Plate and screws were implanted according to the manufacturer's recommendations. In all test groups a short PHILOS plate with 3 shaft holes was used (Fig. 1). In all osteosynthesis the 3 shaft holes (Section F-H) were occupied with bicortical head locking screws (LS 3.5, Fig. 2a).

The screw length was determined by measuring the distance between the lateral and the medial cortex or the subchondral bone using the measurement tool provided by the manufacturer. In order to have comparable screw lengths the second humerus of a pair always received the same screw lengths, which were measured for the contralateral humerus of the pair.

All humeri were embedded in PMMA cement (Polymethylmethacrylat, Technovit 3040, Heraus Kulzer, Wertheim, Germany) to allow for fixation of the specimens in the material testing machine.

\section{Biomechanics of DLS}

We measured the loading of screws and their load distribution in a locking plate osteosynthesis model of a long bone diaphyseal fracture using standard locking screws or dynamic locking screws. Then we used these results along with information about the distribution of bone mineral densitiy (BMD) of the humeral head to develope a finite elements model (FEM) for estimating screw loading and load distribution among the screws in a proximal humerus plate osteosynthesis using standard locking screws versus DLS.

\section{Testing}

Varus bending and axial rotation tests were performed to evaluate biomechanical characteristics of both osteosynthesis (dynamic osteosynthesis vs. conventional osteosynthesis). A biaxial servo-hydraulic material testing machine (MTS, 858 MiniBionix II, MN, USA) was used with a specifically designed loading jig and a cyclic loading protocol.

The different test groups were arranged in a pair wise fashion:

1. Bending test $(n=12)$

a. standard locking screws $(n=6$, PHILOS with LS)

b. dynamic locking screws $(n=6$, PHILOS with DLS)

2. Rotation test $(n=12)$

a. standard locking screws $(n=6$, PHILOS with LS)

b. dynamic locking screws $(n=6$, PHILOS with DLS) 
At the proximal end of the PHILOS plate and at the minor tubercle, markers of the 3D motion analysis system (Winbiomechanics, Zebris, Isny, Germany) were fixed. The system recorded rotation and translation in all six degrees of freedom and by that the relative motion between the PHILOS plate and the humeral head were detected. For defining the coordinate system in the humeral head, landmarks were chosen to approximate the center of the coordinate system in the center of the humeral head.

For the bending test, the embedded distal humeral shaft was fixed to the actuator of the servo-hydraulic testing machine. The humeral head was fixed via a ballbearing device to minimise shear forces (Fig. 3). Specimens were cyclically loaded until failure occurred. Initially, the loading ranged from $+10 \mathrm{~N}$ (tension) to $-50 \mathrm{~N}$ (compression), while the load magnitude in compression increased stepwise by $5 \mathrm{~N}$ every 100 load cycles. The loading rates for all load magnitudes were $5 \mathrm{~mm} / \mathrm{sec}$. This resulted in a compressive load magnitude of $50 \mathrm{~N}$ after 100 load cycles, $100 \mathrm{~N}$ after 1000 load cycles, $150 \mathrm{~N}$ after 2000 load cycles etc. The bending tests were carried out in a cantilevered fashion to produce a varus (valgus-tension) bending moment. The lever arm was between the PHILOS plate and the point of load application and accounted for approximately $45 \mathrm{~mm}$. This resulted in an approximate initial bending moment from $0.45 \mathrm{Nm}$ in valgus to $2.25 \mathrm{Nm}$ in varus. While

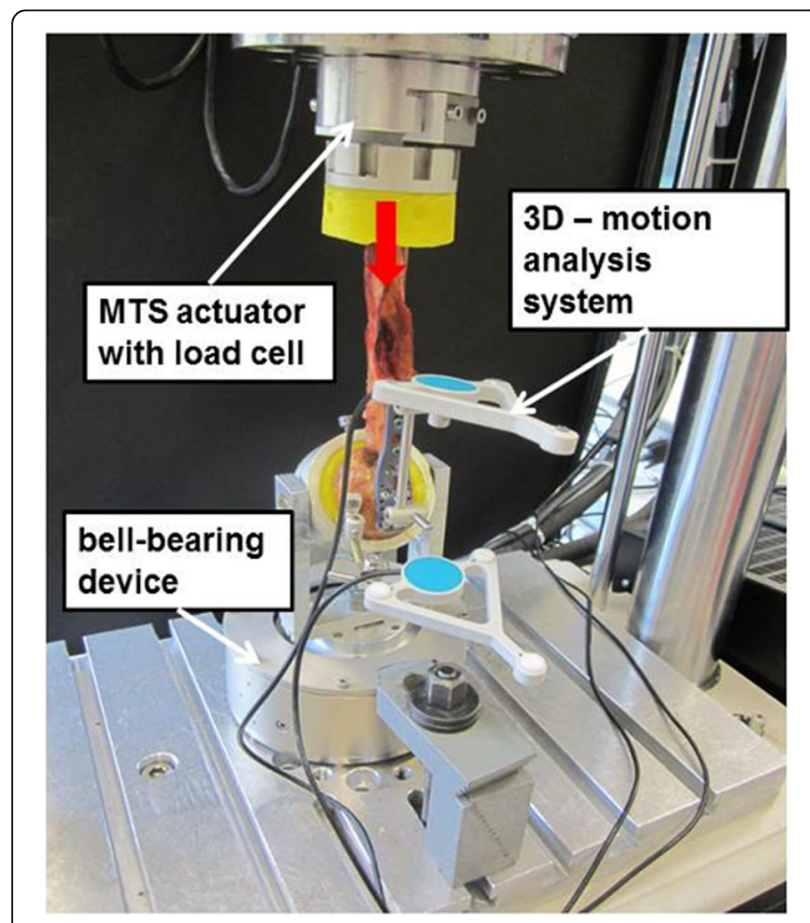

Fig. 3 Setup for the varus bending test the bending moment in valgus was kept constant, the bending moment in varus increased to $4,5 \mathrm{Nm}$ after 1000 loading cycles and to $6,75 \mathrm{Nm}$ after 2000 loading cycles. Specimens were cyclically loaded until obvious failure of the screw bone fixation. In the post testing data analysis, failure was defined as an increase of angular tilting in varus of more than 0.5 degrees within 100 load cycles.

For axial rotation testing, the humeral head was fixed to the actuator of the servohydraulic testing machine while rotation in the anterior-posterior plane was allowed. The applied torque acted along the humeral shaft axis. The distal end of the humerus was fixed to a xy-bearing table to minimise shear forces (Fig. 4). Specimens were cyclically loaded with a constantly increasing torque and a constant axial load of $20 \mathrm{~N}$. The sinusoidal torque was applied with $0.25 \mathrm{~Hz}$ and initially ranged from -0.5 to $+0.5 \mathrm{Nm}$. With each load cycle, the range in both directions was increased by $0.0025 \mathrm{Nm}$, e.g. after 1000 cycles the torque ranged from -3.0 to $+3.0 \mathrm{Nm}$. Every 100 load cycles, motion data was recorded and maximum rotation of the humeral head to the plate was determined. Specimens were loaded until failure of the screw/bone fixation. Failure was defined as an axial rotational motion larger than four degrees during one load cycle.

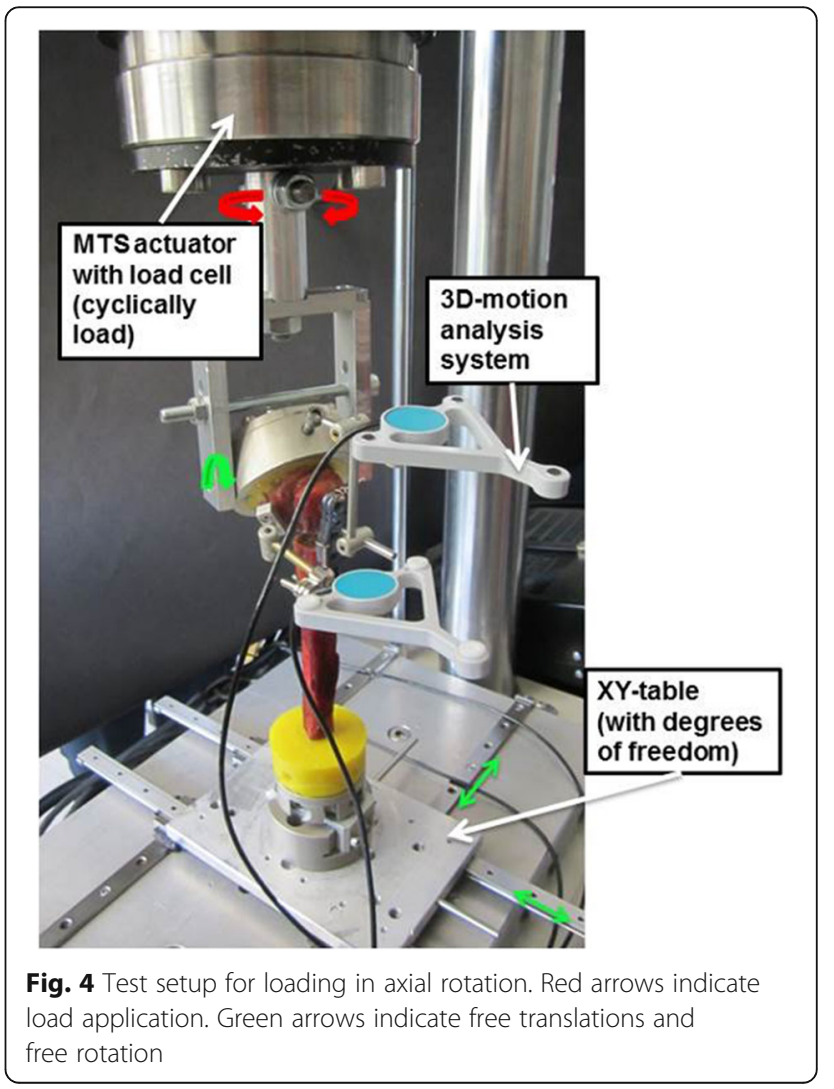




\section{Statistical analysis}

The numbers of failure cycles by the standard LS 3.5 $\mathrm{mm}$ were compared with the numbers of failure cycles by the DLS $3.7 \mathrm{~mm}$ screws (in varus bending test and in axial torsion test). Due to the small sample size nonnormal distribution of the data was assumed and the groups were compared using the Wilcoxon signed rank test. All results are reported as median with range. We also analysed the correlation between the number of failure cycles and the BMD values using linear regression analysis.

\section{Results}

\section{Varus bending testing}

In the varus bending testing all specimen pairs failed by loosening of the screws in the humeral head and subsequent in varus tilting of the head relative to the plate. The group of the LS 3.5 screws reached 2901 (range 601 to 5201) load cycles until failure of the fixation occurred, while the group of the DLS 3.7 screws failed after 3731 (range 2001 to 5601) cycles. This corresponds to a median loading of $195 \mathrm{~N}$ and $235 \mathrm{~N}$ for the LS 3.5 and the DLS 3.7 group, respectively.

The comparison of both test groups shows that each test specimens with DLS 3.7 screws sustained a higher number of load cycles until failure than the corresponding contralateral humeri with the standard (LS 3.5) screws (Fig. 5). Failure cycle using DLS 3.7 screws were 400-1600 cycles higher than the failure cycle using LS 3.5 screws. The difference between the two groups were significant $(p=0.028)$.
BMD

The specimens showed a strong positive correlation $\left(R^{2}=0.950, p=0.005\right)$ between the BMD and the failure cycle in varus bending in the DLS-group. We found strong positive correlation $\left(R^{2}=0.950, p=0.005\right)$ in the group of the DLS. This correlation between BMD and failure cycle is weaker in the LS-group. $\left(R^{2}=0.427, p=\right.$ 0.232). There was no significant difference of BMD between groups.

\section{Axial rotation testing}

In the torsional load case (axial rotation) all specimens failed by loosening of the screws in the humeral head and subsequent excessive torsion of the head relative to the plate. The LS-group reached a median of 1101 (range 501 to 1501) load cycles until failure of the fixation occurred, while the DLS-group failed after 1401 (range 401 to 2201) load cycles. These failure cycles correspond to a median torque of $3.25 \mathrm{Nm}$ and $4.09 \mathrm{Nm}$ for the LS- and the DLS-group, respectively (Fig. 6).

The comparison of both test groups showed that of the six specimen pairs, the DLS-group showed 3 times a higher number of load cycles and the LS-group showed twice a higher number of load cycles until failure, while one specimen pair showed identical failure cycles. There was no statistical difference between the two gest groups $(p=0.225)$. So all test specimens with the dynamic fixation sustained a higher or similar number of load cycles until failure than the corresponding contralateral humeri with conventional standard locking screws.

The specimens in both groups showed only a weak correlation between the BMD and failure cycle (LS-

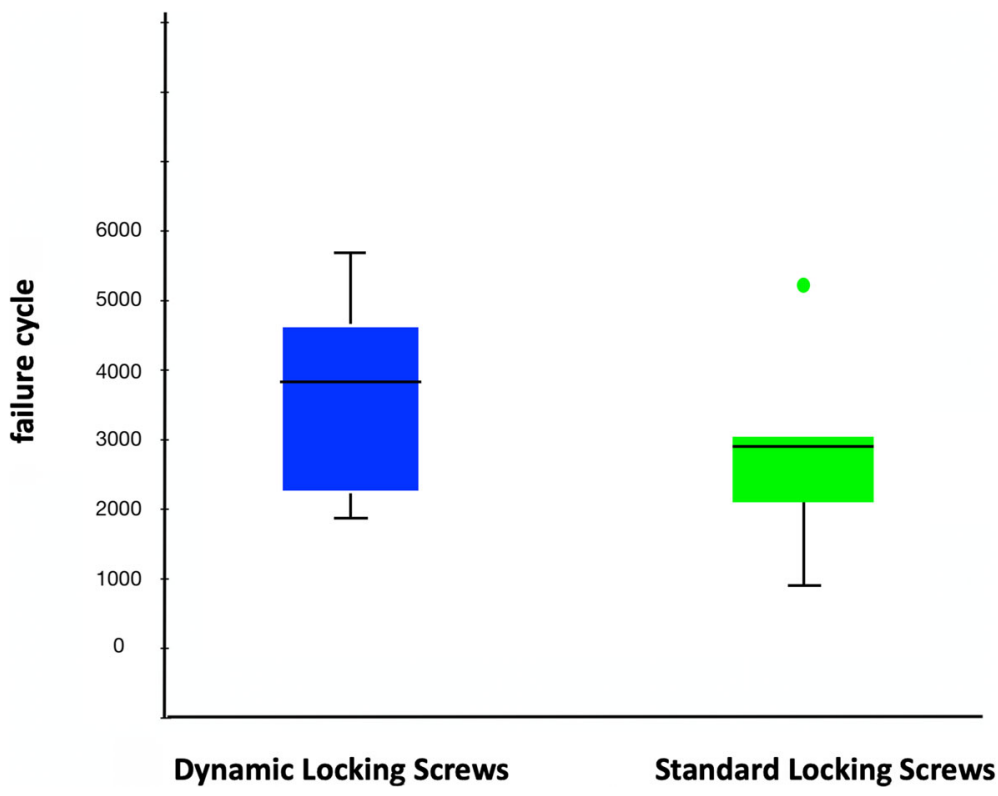

Fig. 5 Failure cycle of the bending test in boxplot for DLS and standard (LS) screws 


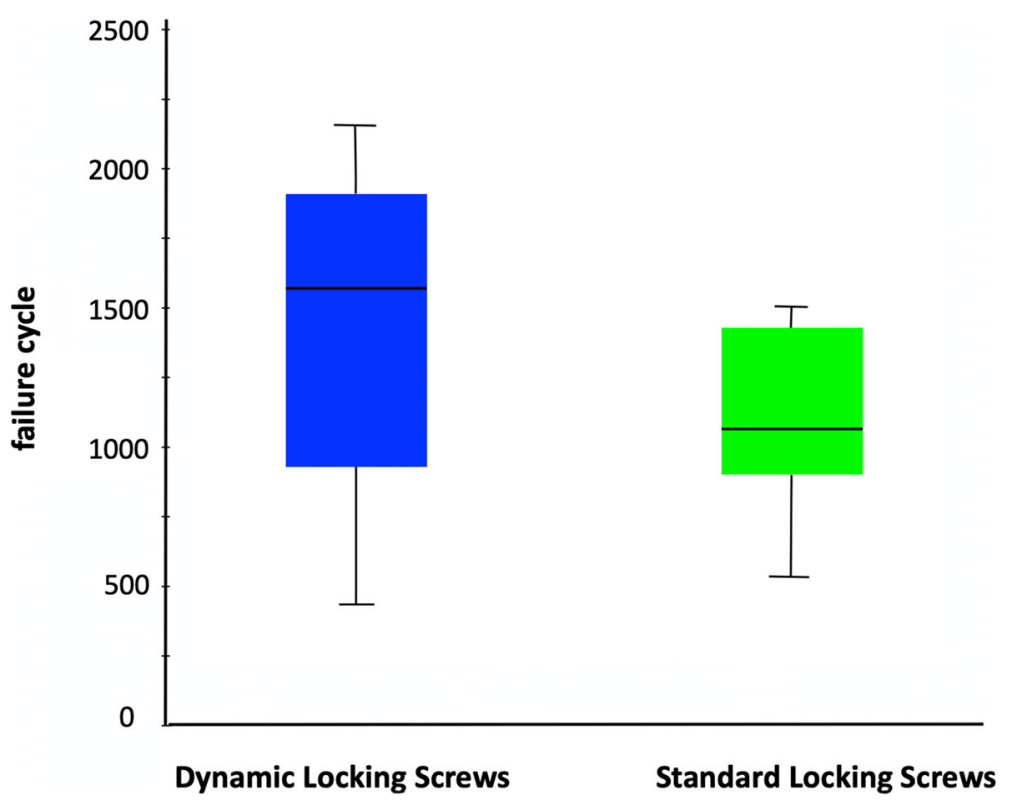

Fig. 6 Failure cycle of the torsion test in boxplot for dynamic (DLS) and standard (LS) screws

group: $R^{2}=0.483, \quad p=0.126 ;$ DLS-group: $R^{2}=0.196$, $p=0.379)$.

FEM analysis of screw load distribution in PHILOS using standard or dynamic locking screws

We found a lower load maximum and a more evenly distributed loading pattern in the model for dynamic locking screws compared to standard locking screws (Fig. 7).

\section{Discussion}

The most important finding of this biomechanical study demonstrated higher loads to failure for dynamic locking screws (DLS) in comparison with standard locking screws (LS). Common treatment options for proximal humeral fractures are still associated with high complication rates $[2,18,19]$. In search for improving the biomechanical properties of fracture fixation in healthy and osteoporotic bone, DLS were developed [29]. The general mechanical properties of DLS had been studied earlier in biomechanical studies $[9,10]$. In angle stable plate osteosynthesis of the proximal humerus, it was clinically demonstrated that the mechanical load is distributed more equally among the screws, if DLS are used instead of standard LS (Fig. 7) [12].

With the present biomechanical study, we verified a higher failure load using DLS versus LS in angle stable plate osteosynthesis of the proximal humerus in a fracture model. This might lead to reduced secondary dislocations and improved or at least more consistent clinical outcomes after osteosyntheses of proximal humeral fractures.

Dynamic PHILOS plate fixation leads to better screw anchorage in proximal humeral fractures in comparison to the conventional fixation. By using the dynamic fixation technology 400-1600 cycles more could be applied until failure occurred, whereas the conventional locking plate fixation failed significantly earlier in varus bending testing. These findings were observed both in proximal humeri with normal BMD and in osteoporotic bone with reduced BMD.

These positive findings can be explained by the special design of the dynamic screws, as they enable a relative motion of $0.2 \mathrm{~mm}$ between the head of the screw and the sleeve of the screw $[9,10]$. Thereby, a more homogenous intra- and an inter-screw load distribution of the pin-sleeve-construct of the DLS 3.7 can be achieved. This has two advantages: 1) Intra-screw: the force is distributed over a longer distance along the screw axis. 2) Inter-screw: because of the reduced rigidity of the plate-screw construct, a certain damping effect occurs.

The motion between the screw and the plate leads to a more homogeneous load distribution over all implanted screws. By using the standard locking screws (LS 3.5), $60 \%$ of the peak stress applies to the two proximal platescrews (A position of the PHILOS plate). With the dynamic locking screws (DLS 3.7), the stress can be reduced to $40 \%$ in these particular screws [12].

The design of the screw tip of the DLS 3.7 is likely to also have a positive effect on screw anchorage and might 


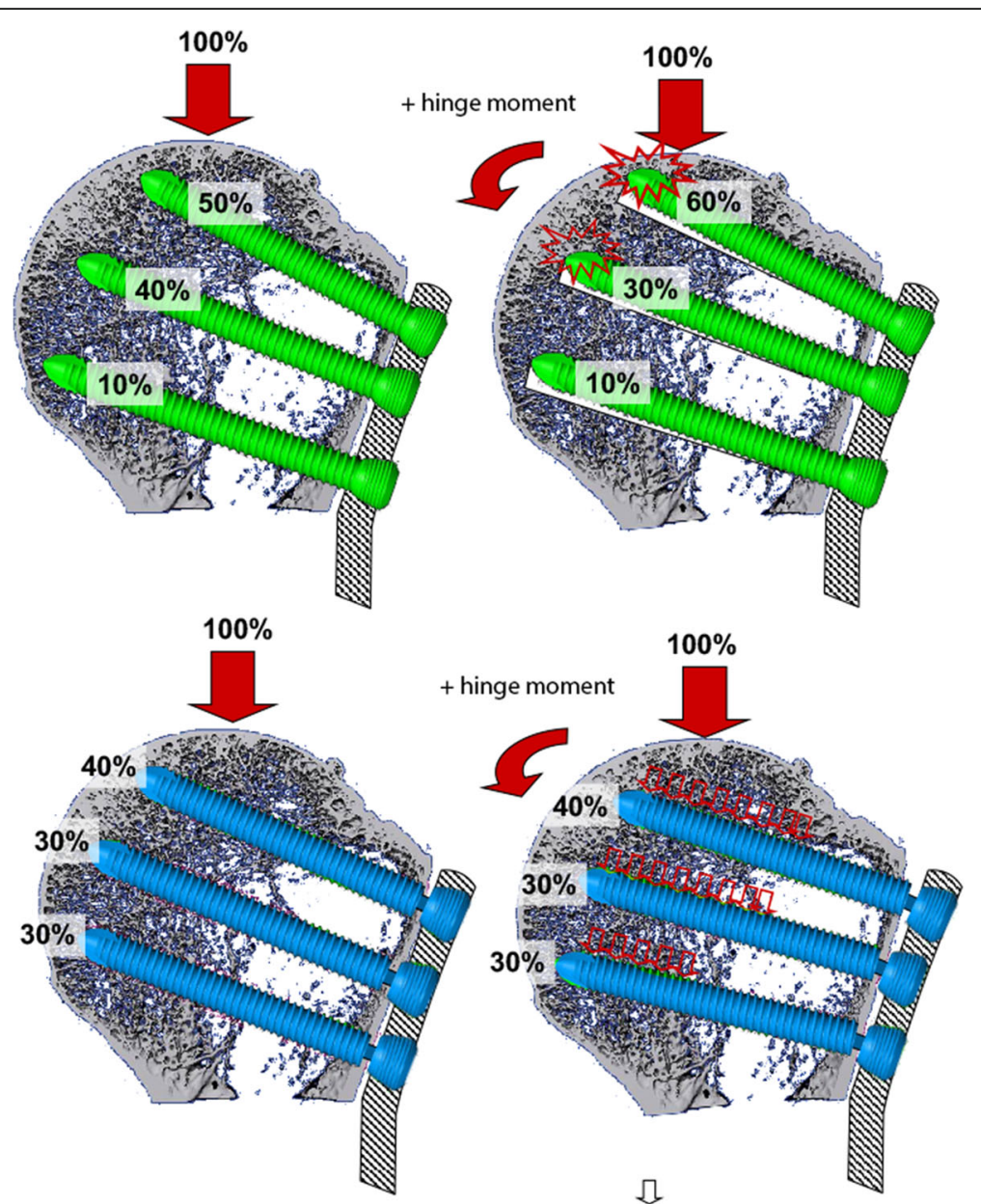

Fig. 7 Screw load distribution with standard locking screws (green) versus dynamic locking screws (blue)

help to prevent the screw from cut-out. Compared to LS $3.5(3.5 \mathrm{~mm})$ the DLS $3.7(3.7 \mathrm{~mm})$ has a round tip and fewer sharp edges at the end of the screw. This probably contributes to a reduction of peak interface stresses between the tip of the screw and the bone, preventing screw loosening and failure.

DLS probably don't achieve the same rigid biomechanical properties as cement augmented screws $[23,28]$. But the idea of a more dynamic osteosynthesis demonstrated its beneficial biomechanical principles in the setup of this study and might contribute to improve the failure rates in standard fracture treatments, especially in scenarios with poor bone substance like proximal humeral fractures.

Plate fixation using dynamic locking screws for the treatment of proximal humerus fractures demonstrated more load cycles until failure compared to standard locking plate osteosynthesis. In the clinical setting, this could provide a safer osteosynthesis and less secondary failures. So, patients could potentially benefit from the clinical application of dynamic locking screws in proximal humerus plate osteosynthesis. Although we demonstrated successful fracture fixation, further studies are needed before DLS can be recommended as standard implants in proximal humeral plate osteosynthesis.

\section{Conclusions}

In this biomechanical study using a model of proximal humeral plate osteosynthesis, we demonstrated higher loads to failure for dynamic locking screws (DLS) in comparison with standard locking screws (LS). This might help to reduce secondary dislocations. A proximal humerus plate with DLS could potentially present a biomechanically optimized implant for clinical application in patients with fractures of the proximal humerus, especially in comminuted and osteoporotic situations.

\section{Acknowledgements}

Not applicable.

Authors' contributions

GS, and SD analysed the data and wrote major parts of the manuscript. AA $T F$, and US supervised the study. WS collected the data. CK analysed the 
data, wrote major parts of the manuscript and revised the whole manuscript. All authors read and approved the final manuscript.

\section{Funding}

Open Access funding enabled and organized by Projekt DEAL.

\section{Availability of data and materials}

The datasets generated and analysed during the current study are available from the authors on reasonable request.

\section{Ethics approval and consent to participate}

This study was approved by our university's ethics committee.

\section{Consent for publication}

Not applicable.

\section{Competing interests}

The authors declare that they have no competing interests.

\section{Author details}

${ }^{1}$ Sportsclinic Ravensburg, Ravensburg, Germany. ${ }^{2}$ Department of Trauma and Reconstructive Surgery, BG Klinik, University of Tübingen, Schnarrenbergstr. 95, 72076 Tübingen, Germany. ${ }^{3}$ Department of Orthopaedics and Traumatology, University of Salzburg, Salzburg, Austria. ${ }^{4}$ Center for Musculoskeletal Surgery, Charité - University Medical Center Berlin, Berlin, Germany. ${ }^{5}$ Department of Biomechanics, University of Innsbruck, Innsbruck, Austria.

\section{Received: 22 June 2020 Accepted: 22 September 2020}

Published online: 12 October 2020

\section{References}

1. Agudelo J, Schürmann M, Stahel P, Helwig P, Morgan SJ, Zechel W et al (2007) Analysis of efficacy and failure in proximal humerus fractures treated with locking plates. J Orthop Trauma 21:676-681

2. Alispahic N, Brorson S, Bahrs C, Joeris A, Steinitz A, Audigé L (2020) Complications after surgical management of proximal humeral fractures: a systematic review of event terms and definitions. BMC Musculoskelet Disord 21:1-6 epub ahead of print

3. Biermann N, Prall WC, Böcker W, Mayr HO, Haasters F (2019) Augmentation of plate osteosynthesis for proximal humeral fractures: a systematic review of current biomechanical and clinical studies. Arch Orthop Trauma Surg 139:1075-1099

4. Brianza S, Plecko M, Gueorguiev B, Windolf M, Schwieger K (2010) Biomechanical evaluation of a new fixation technique for internal fixation of three-part proximal humerus fractures in a novel cadaveric model. Clin Biomech 25:886-892

5. Brunner F, Sommer C, Bahrs C, Heuwinkel R, Hafner C, Rillmann P et al (2009) Open reduction and internal fixation of proximal humerus fractures using a proximal humeral locked plate: a prospective multicenter analysis. J Orthop Trauma 23:163-172

6. Cha H, Park KB, Oh S, Jeong J (2017) Treatment of comminuted proximal humeral fractures using locking plate with strut allograft. J Shoulder Elb Surg 26:781-785

7. Court-Brown CM, Cattermole H, McQueen MM (2002) Impacted valgus fractures (B1.1) of the proximal humerus. The results of non-operative treatment. J Bone Joint Surg (Br) 84:504-508

8. Court-Brown CM, McQueen M (2009) Open reduction and internal fixation of proximal humeral fractures with use of the locking proximal humerus plate. J Bone Joint Surg Am 91:2771-2772

9. Doebele S, Horn C, Eichhorn S, Buchholtz A, Lenich A, Burgkart R et al (2010) The dynamic locking screw (DLS) can increase interfragmentary motion on the near cortex of locked plating constructs by reducing the axial stiffness. Langenbeck's Arch Surg 395:421-428

10. Doebele S, Gardner M, Schröter S, Höntzsch D, Stöckle U, Freude T (2014) DLS 5.0 - the biomechanical effects of dynamic locking screws. PLoS One 9: e91933

11. Edwards SL, Wilson NA, Zhang L-Q, Flores S, Merk BR (2006) Two-part surgical neck fractures of the proximal part of the humerus. A biomechanical evaluation of two fixation techniques. J Bone Joint Surg Am $88: 2258-2264$
12. Freude $T$, Schroeter S, Plecko M, Bahrs C, Martetschlaeger F, Kraus TM et al (2014) Dynamic-locking-screw (DLS) leads to less secondary screw perforations in proximal humerus fractures. BMC Musculoskelet Disord 15:194

13. Knierzinger D, Crepaz-Eger U, Hengg C, Kralinger F (2020) Does cement augmentation of the screws in angular stable plating for proximal humerus fractures influence the radiological outcome: a retrospective assessment. Arch Orthop Trauma Surg. https://doi.org/10.1007/s00402-020-03362-1

14. Horn J, Gueorguiev B, Brianza S, Steen H, Schwieger K (2011) Biomechanical evaluation of two-part surgical neck fractures of the humerus fixed by an angular stable locked intramedullary nail. J Orthop Trauma 25:406-413

15. Kralinger F, Blauth M, Goldhahn J, Käch K, Voigt C, Platz A et al (2014) The influence of local bone density on the outcome of one hundred and fifty proximal humeral fractures treated with a locking plate. J Bone Joint Surg Am 96:1026-1032

16. Krappinger DD, Bizzotto NN, Riedmann SS, Kammerlander CC, Hengg CC, Kralinger FSF (2011) Predicting failure after surgical fixation of proximal humerus fractures. Injury 42:1283-1288

17. Kuang GM, Wong TM, Wu J, Ouyang J, Guo H, Zhou Y, Fang C, Leung FKL, Lu W (2018) Augmentation of a locking plate system using bioactive bone cement: experiment in a proximal humeral fracture model. Geriatr Orthop Surg Rehabil 9:2151459318795312

18. Lode I, Nordviste V, Erichsen JL, Schmal H, Viberg B (2020) Operative versus nonoperative treatment of humeral shaft fractures: a systematic review and meta-analysis. J Shoulder Elb Surg 15:1058-2746

19. Lorenz G, Schönthaler W, Huf W, Komjati M, Fialka C, Boesmueller S (2020) Complication rate after operative treatment of three- and four-part fractures of the proximal humerus: locking plate osteosynthesis versus proximal humeral nail. Eur J Trauma Emerg Surg. https://doi.org/10.1007/s00068-02001380-7 epub ahead of print

20. Martetschläger F, Siebenlist $S$, Weier M, Sandmann G, Ahrens P, Braun K et al (2012) Plating of proximal humeral fractures. Orthopedics 35:e1606e1612

21. Röderer G, Erhardt J, Kuster M, Vegt P, Bahrs C, Kinzl L et al (2011) Second generation locked plating of proximal humerus fractures: a prospective multicentre observational study. Int Orthop 35:425-432

22. Röderer G, Moll S, Gebhard F, Claes L, Krischak G (2011) Side plate fixation vs. intramedullary nailing in an unstable medial femoral neck fracture model: a comparative biomechanical study. Clin Biomech 26:141-146

23. Röderer G, Scola A, Schmölz W, Gebhard F, Windolf M, Hofmann-Fliri L (2013) Biomechanical in vitro assessment of screw augmentation in locked plating of proximal humerus fractures. Injury 44:1327-1332

24. Siebenbürger G, Helfen T, Biermann N, Haasters F, Böcker W, Ockert B (2019) Screw-tip augmentation versus standard locked plating of displaced proximal humeral fractures: a retrospective comparative cohort study. J Shoulder Elb Surg 28:1326-1333

25. Siffri PC, Peindl RD, Coley ER, Norton J, Connor PM, Kellam JF (2006) Biomechanical analysis of blade plate versus locking plate fixation for a proximal humerus fracture: comparison using cadaveric and synthetic humeri. J Orthop Trauma 20:547-554

26. Sproul RC, lyengar JJ, Devcic Z, Feeley BT (2011) A systematic review of locking plate fixation of proximal humerus fractures. Injury 42:408-413

27. Südkamp N, Bayer J, Hepp P, Voigt C, Oestern H, Kääb M et al (2009) Open reduction and internal fixation of proximal humeral fractures with use of the locking proximal humerus plate: results of a prospective, multicenter, observational study. J Bone Joint Surg Am 91:1320-1328

28. Unger S, Erhart S, Kralinger F, Blauth M, Schmoelz W (2012) The effect of in situ augmentation on implant anchorage in proximal humeral head fractures. Injury 43:1759-1763

29. Vicenti G, Pesce V, Tartaglia N, Abate A, Mori CM, Moretti B (2014) Micromotion in the fracture healing of closed distal metaphyseal tibial fractures: a multicentre prospective study. Injury 45(Suppl 6):S27-S35

30. Voigt C, Geisler A, Hepp P, Schulz AP, Lill H (2011) Are polyaxially locked screws advantageous in the plate osteosynthesis of proximal humeral fractures in the elderly? A prospective randomized clinical observational study. J Orthop Trauma 25:596-602

\section{Publisher's Note}

Springer Nature remains neutral with regard to jurisdictional claims in published maps and institutional affiliations. 